\title{
Use of proteomics to identify highly abundant maternal factors that drive the egg-to-embryo transition
}

\author{
Piraye Yurttas, Eric Morency ${ }^{1}$ and Scott A Coonrod ${ }^{1}$ \\ Weill Graduate School of Medical Sciences, Cornell University, 1300 York Avenue, New York, New York 10065, USA \\ and ${ }^{1}$ College of Veterinary Medicine, Baker Institute for Animal Health, Cornell University, Hungerford Hill Road, \\ Ithaca, New York 14853, USA
}

Correspondence should be addressed to S A Coonrod; Email: sac269@cornell.edu

P Yurttas and E Morency contributed equally to this work

$P$ Yurttas is now at Celmatix, Inc., 7 Hubert Street, New York, New York 10013, USA

\begin{abstract}
As IVF becomes an increasingly popular method for human reproduction, it is more critical than ever to understand the unique molecular composition of the mammalian oocyte. DNA microarray studies have successfully provided valuable information regarding the identity and dynamics of factors at the transcriptional level. However, the oocyte transcribes and stores a large amount of material that plays no obvious role in oogenesis, but instead is required to regulate embryogenesis. Therefore, an accurate picture of the functional state of the oocyte requires both transcriptional profiling and proteomics. Here, we summarize our previous studies of the oocyte proteome, and present new panels of oocyte proteins that we recently identified in screens of metaphase II-arrested mouse oocytes. Importantly, our studies indicate that several abundant oocyte proteins are not, as one might predict, ubiquitous housekeeping proteins, but instead are unique to the oocyte. Furthermore, mouse studies indicate that a number of these factors arise from maternal effect genes (MEGs). One of the identified MEG proteins, peptidylarginine deiminase 6, localizes to and is required for the formation of a poorly characterized, highly abundant cytoplasmic structure: the oocyte cytoplasmic lattices. Additionally, a number of other MEG-derived abundant proteins identified in our proteomic screens have been found by others to localize to another unique oocyte feature: the subcortical maternal complex. Based on these observations, we put forth the hypothesis that the mammalian oocyte contains several unique storage structures, which we have named maternal effect structures, that facilitate the oocyte-to-embryo transition.
\end{abstract}

Reproduction (2010) 139 809-823

\section{Introduction}

The primary cellular functions of the ovulated metaphase II (MII)-arrested mammalian oocyte are to bind and fuse with a sperm, successfully reprogram and combine the two haploid genomes, and facilitate early mitotic divisions until the embryo can initiate and carry out its own molecular programs. Given that the ovulated egg is transcriptionally quiescent and that major embryonic transcription does not initiate until, depending on the species, the two-cell stage or beyond, these changes must be orchestrated post-transcriptionally (Schultz 2002). This reliance on translational control as opposed to transcriptional control is a universal property of oocytes that may allow for the oocyte genome to remain in a more plastic and undifferentiated state in the context of an otherwise highly differentiated cell (Seydoux \& Braun 2006). In order to accomplish this unique regulatory feat, molecular physiology and composition of oocytes are distinct from those of somatic cells. To facilitate the transition from maternal to embryonic control, oocytes need to store and then selectively utilize an abundance of factors. Therefore, as opposed to somatic cells, which divide after doubling their volume, the mouse oocyte grows around 200- to 300-fold in volume without dividing, and during this $\sim 2.5$-week period of growth, there is intense metabolic activity resulting in the synthesis of large amounts of mRNAs, proteins, and macromolecular structures (Yanagimachi 1994). While some portion of this newly made material is specifically required for oocyte function, a number of these factors are likely endowed to the embryo after fertilization to facilitate early cleavage divisions.

In order to gain further insight into factors within the ovulated egg that might mediate the oocyte-to-embryo transition (OET), modern approaches, such as transcriptomics and proteomics, are currently being utilized to probe the molecular foundations of the mammalian oocyte. Transcriptional profiling involves the analysis of changes in mRNA expression levels between different cellular states using DNA microarray technology. 
This technology is very useful for probing the molecular profile of most somatic cells because gene regulation occurs primarily at the level of gene promoters, and the half-life of most transcripts is relatively short. Therefore, any significant changes in transcript levels often directly reflect the time point at which the encoded protein is required and synthesized. Transcript profiling has also been successfully utilized to provide insight into oocyte and early embryo function (Hamatani et al. 2004a, Wang et al. 2004, Zeng et al. 2004). However, as opposed to mRNA from most somatic cells, oocyte mRNA is extremely stable, with the half-life of most transcripts averaging around 12 days (Bachvarova 1981). Also, it has been observed that the ratio of poly(A) to total RNA is higher in oocytes than in somatic cells (Sternlicht \& Schultz 1981). Therefore, given the disequilibrium between transcript levels and encoding proteins, proteomic methods will have to be utilized alongside transcriptional profiling in order to elucidate the true functional state of the oocyte and pre-implantation embryo.

The first proteomic studies documented the repertoire of proteins that are synthesized during oocyte growth and maturation by resolving $\left[{ }^{35} \mathrm{~S}\right]$ radiolabeled proteins on both 1- and 2- dimensional (1D and 2D) gels, and by imaging the labeled proteins using fluorography. Surprisingly, it was found that while the rates of synthesis differ between specific proteins, the overall repertoire of proteins did not appear to change dramatically during growth (Schultz \& Wassarman 1977). This stability suggested to the investigators that, similar to stored mRNAs, many of the proteins synthesized during oocyte growth are actually stored, and function after fertilization. A limitation of these early experiments was that the identity of the resolved proteins could not be determined because Edman degradation was not sensitive enough to detect limited amounts of protein, and because mammalian genomes had yet to be sequenced (Patterson \& Aebersold 2003). In the early 1990s, however, mass DNA sequencing of cDNAs, obtained from mRNAs of various tissues, allowed for the generation of large datasets of gene sequences. Soon thereafter, complete genomic sequences were also obtained - with the first scan of the human genome being completed in the late 1990s. With this genomic information being available publicly now, the rapid identification of proteins was only limited by the ability to obtain peptide masses that could be compared with database peptide sequence masses deduced from gene annotations. This breakthrough came with the development of matrix-assisted laser desorption ionization and time-of-flight mass spectrometers, which came into common use in the mid-to-late 1990s (Eng et al. 1994). With these elements in place, it then became feasible to utilize proteomics to help resolve the proteinaceous nature of the mammalian egg. Thus, beginning in the late 1990s, we and others began coupling 1D and 2D gel electrophoresis with mass spectrometry to catalog the murine egg proteome. It should be noted here that one current limitation to oocyte proteomic methods is that only the most abundant proteins in each sample can be detected. Additionally, given the current limits of sensitivity, we have yet to identify many key reprogramming factors and, therefore, it will be important over the coming years to further enrich the proteomic catalog for oocytes as the state of the art improves.

\section{Summary of previous findings: use of proteomics to help elucidate the mechanisms of oocyte maturation, fertilization, and early development}

\section{Oocyte maturation: use of a differential expression proteomic screen to identify putative maturation- related proteins}

Significant insight can be gained into the molecules underlying specific cellular functions by comparing the molecular composition of a cell in two different states. Proteomics holds several advantages over transcriptomics when this type of differential expression analysis is performed because, as mentioned above, the presence of a specific transcript within a cell does not always directly correlate with levels of the encoded protein. Furthermore, proteomics also allows for the detection of changes in post-translational modification. Therefore, we decided to utilize proteomics to identify proteins that are differentially expressed or modified during murine oocyte maturation (Vitale et al. 2007). For these experiments, we isolated proteins from $\sim 500$ germinal vesicle (GV) and MII-stage oocytes, and resolved these proteins on 2D gels followed by silver staining. We found that the repertoire of expressed proteins between each stage appeared remarkably similar, with only 12 proteins appearing to be differentially expressed. To gain insight into the molecular factors driving the maturation process, we then utilized mass spectrometry to identify the differentially expressed proteins. Results showed that TACC3, heat shock protein (HSP) 105, STI1, ADSS, lipocalin (LCN1), and lysozyme 1 appeared to be downregulated during maturation, while one protein, TCTP, appeared to be up-regulated during maturation. As opposed to being either down- or up-regulated, it is also possible that these molecules were post-translationally modified during maturation, and that the modified protein was not detected on the corresponding gel. Five proteins, PDCD6IP, importin- $\alpha 2$, nudix, nucleoplasmin 2 (NPM2), and spindlin, were identified in both samples. The mass and isoelectric points of these five proteins were slightly different between the GV and MII stage, suggesting that these molecules were, in fact, posttranslationally modified during maturation (Vitale et al. 2007). This prediction was supported by observations that spindlin and NPM2 are phosphorylated during 
oocyte maturation (Oh et al. 1997, Vitale et al. 2007). We decided to further characterize one molecule identified in the differential screen, TACC3 (Hao et al. $2002)$, based on its similarity (35\% identity) with the Xenopus oocyte protein, maskin, a cytoplasmic polyadenylation element-binding protein-associated factor. We found that TACC 3 expression initiates during oocyte growth, and is primarily restricted to the cytoplasm. Recently, it was observed that maskin/TACC3 is required for microtubule anchoring at the centrosome (Albee \& Wiese 2008), and that TACC3 is essential for spindle assembly and cell survival (Schneider et al. 2007). Therefore, it will be of interest to determine if TACC3 also plays a key role in spindle assembly during meiosis in the mammalian oocyte. Importantly, similar to TACC3, most of the other proteins identified in our differential expression screen have been previously found to play important roles in mitosis in Xenopus and in meiosis in invertebrates; however, their roles in mammalian oocyte maturation are yet to be investigated. Thus, we believe that further functional analysis of these candidate meiotic factors would likely prove fruitful.

\section{Fertilization: coupling surface labeling with proteomics to identify proteins involved in sperm-egg interaction}

We have also combined proteomics technology with surface labeling techniques to resolve the identity of egg surface (oolemmal) proteins. For these experiments, we labeled viable zona-free oocytes with biotin, resolved the extracted proteins on 2D gels, and then identified the surface-labeled proteins by probing the blots with streptavidin. Results showed that at least 50 surfacelabeled proteins could be visualized using the procedure when $\sim 800$ oocytes were used as input (Coonrod et al. 1999). We next investigated whether any of these surface proteins were attached to the egg surface via glycosylphosphatidylinositol (GPI) anchors by treating the labeled eggs with the anchor-cleaving enzyme, PI-PLC. Results showed that the most abundant surface-labeled protein $(70 \mathrm{kDa}$, pl 5) was PI-PLC sensitive. Furthermore, we found that PI-PLC-treated oocytes could not be fertilized by sperm, suggesting that the $70 \mathrm{kDa}$ protein is involved in sperm-egg interaction (Coonrod et al. 1999). Eventually, this protein was identified as CD55 by other investigators who then also confirmed its role in fertilization (Alfieri et al. 2003).

Interestingly, our surface labeling experiments also found that the molecular chaperones HSP70 (HSP1b), HSP90a, GRP94, BiP (GRP78), ORP150 (hypoxia up-regulated 1), calreticulin, calnexin, and PDI are abundantly represented on the oolemma (Calvert et al. 2003). Molecular chaperones have been detected on the surface of other cell types, and it is thought that one mechanism by which these proteins escape from the endoplasmic reticulum (ER) to the cell surface is by sterically preventing the KDEL retention signal from binding to the retention receptors (Altmeyer et al. 1996). While the potential functions of the molecular chaperones on the egg surface remain unclear, one recent report indicated that oolemmal calreticulin likely plays a role in sperm-egg binding and signal transduction events during fertilization (Tutuncu et al. 2004). Another potential, yet to be explored, role for oolemmal HSPs is in the formation of the zona pellucida during oocyte growth. Given that zona proteins are first targeted to the plasma membrane prior to incorporation into the zona pellucida matrix and that the major function of molecular chaperones is to promote protein folding, it is possible that oolemmal chaperone proteins could facilitate the incorporation of zona proteins into the maturing zona matrix during assembly (Liang et al. 1990).

\section{OET: proteomic analysis of the ovulated, fertilization-competent oocyte identified a subset of highly abundant oocyte-restricted proteins that appear to be required for early development}

The oocyte is unique among cell types in that it has the ability to transition from a terminally differentiated state (the egg will die if not fertilized) to one of totipotency within a few hours if fertilization is successful. In an effort to gain a better understanding of the molecular mechanisms driving this transformative process, we resolved proteins from ovulated fertilization-competent oocytes on 2D gels, stained the gels with Coomassie, and identified some of the most abundant factors using mass spectrometry. Given the unique nature of this process, we predicted that expression of the molecular factors driving the OET would likely be restricted to the egg. Therefore, during our initial studies, we chose to further characterize three highly abundant proteins identified in our screen, cytosolic phospholipase $\mathrm{A} 2 \gamma(\mathrm{CPLA} 2 \gamma$, PLA2G4C), NPM2, and peptidylarginine deiminase 6 (PADI6), because computational analysis of EST databases suggested that the expression of these proteins was restricted to the oocyte and early embryo. A summary of our findings for each of these factors is presented below.

\section{Cytosolic phospholipase $A 2 \gamma$}

Analysis of the cDNA sequence encoding the first protein (MW $\sim 67 \mathrm{kDa}$, pl 5.7) that we cloned from the oocyte proteome found that this molecule is $\sim 56 \%$ identical to human cPLA2 $\gamma$ (Vitale et al. 2005). Others have reported that the human CPLA2 $\gamma$ ortholog does not appear to be expressed in ovarian tissue but, instead, is abundantly expressed in the heart and skeletal muscle (Underwood et al. 1998). However, according to the Amazonia gene expression database, abundant levels of PLA2G4C RNA can be detected in studies probing human oocytes in isolation from the ovary (http:// amazonia.transcriptome.eu/). Importantly, mouse CPLA2 $\gamma$ differs from its human ortholog in that it contains 
a lipase consensus sequence, but lacks a calciumbinding domain found in other PLA2 enzymes. Through northern blot analysis and immunohistochemistry, we demonstrated that, as predicted, CPLA $2 \gamma$ expression is restricted to oocytes and early embryos in mice. With respect to its subcellular localization, we observed that cPLA2 $\gamma$ mainly localizes to the cortical regions, nucleoplasm, and multivesicular aggregates (MVAs; further discussed below) of oocytes. Interestingly, in embryos, the cytoplasmic cPLA2 $\gamma$ staining is asymmetrically restricted to the apical cortex (Vitale et al. 2005). It is also worth noting that while cPLA2 $\gamma$ expression does appear to be mainly limited to oocytes and preimplantation embryos in healthy mice, we recently found the expression of this molecule to be highly up-regulated within the intestinal epithelium of mice that had been infected with Trichinella spiralis. This observation suggests that CPLA2 $\gamma$ may also play a major role in the propagation of the inflammatory response following nematode infection (Brown et al. 2008). The possible requirements of cPLA2 $\gamma$ for such apparently diverse functions remain unclear; however, efforts are underway to generate Pla2g $4 \mathrm{C}$ mutant mice to carry out functional studies.

\section{Nucleoplasmin 2}

Another protein spot (MW $\sim 33 \mathrm{kDa}$, pl 5.0) was originally identified in our egg maturation study as increasing in mass and acidity in MII versus GV oocytes, suggesting it becomes phosphorylated during maturation. We then identified this protein as NPM2 using mass spectrometry. Subsequent database searches suggested that the expression pattern of this protein is restricted to oocytes and early embryos. Accordingly, we generated an NPM2-specific antibody and demonstrated by western blotting that the increase in mass of NPM2 during oocyte maturation is phosphatase sensitive, and that NPM2 appears to retain the phosphorylation modification through the pronuclear stage of development, after which it becomes dephosphorylated at the two-cell stage and remains in this form throughout the rest of pre-implantation development. Immunofluorescence analysis of NPM2 localization showed that NPM2 primarily localizes to the nucleus in oocytes and early embryos. Interestingly, NPM2 strongly localizes to the oocyte cortex in MII-arrested oocytes (the stage at which NPM2 becomes phosphorylated), suggesting that the kinase responsible for phosphorylating NPM2 may be cortically localized or that phosphorylated NMP2 undergoes a structural transition that allows it to interact with other cortically localized factors (Vitale et al. 2007). In 2004, investigators utilized an Npm2-null mouse line to show that maternally derived NPM2 is required for female fertility via its critical role in heterochromatin formation around the nucleolus and in nucleolar organization in oocytes (Burns et al. 2003). It will be interesting to further investigate the role of NPM2 during oogenesis and pre-implantation development, and also to establish what role phosphorylation of NPM2 plays in this process.

\section{Peptidylarginine deiminase 6}

PADI6 (MW $\sim 75 \mathrm{kDA}, \mathrm{pl} 5.5$ ) was originally cloned from the 2D egg proteome gel (Fig. 1) based on its abundance. We decided to focus on further characterization and functional analysis of PADI6 after bioinformatic database criteria suggested that PADI6 expression was almost entirely limited to the oocyte and preimplantation embryo. Furthermore, alignment of the deduced PADI6 amino acid sequence with database sequences indicated that PADI6 represented a new member of a poorly characterized enzyme family: the
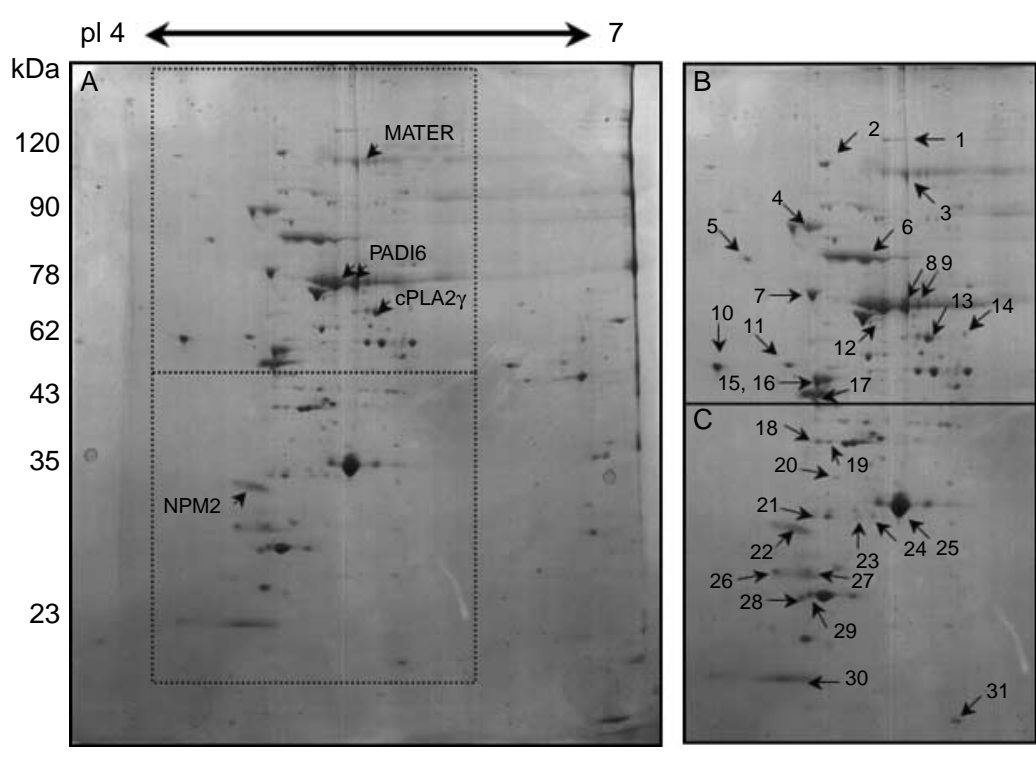

Figure 1 Coomassie-stained 2D SDS-PAGE gel of metaphase II-arrested oocytes. (A) The entire gel highlighting the oocyte and early embryo-restricted proteins that were identified by this method. ( $B$ and $C$ ) Magnified sections of the gel (outlined by dotted lines in (A)) showing all the spots that were cored and analyzed by mass spectrometry. The proteins contained in these spots are listed and described in Table 1. 
PADIs. We then confirmed by northern blotting, RT-PCR, and immunohistochemistry that PADI6 expression is mainly restricted to the oocyte and early embryo - with PADI6 first being expressed in primordial oocyte follicles and persisting, at the protein level, throughout pre-implantation development to the blastocyst stage (Wright et al. 2003). Next, we utilized a Padi6-null mouse line to show that inactivation of PADI6 leads to female infertility in mice, with the Padi6-null developmental arrest occurring at the two-cell stage (Esposito et al. 2007). Furthermore, we showed that the likely cause of this developmental arrest is incomplete activation of embryonic gene transcription, which initiates at the two-cell stage in the mouse (Yurttas et al. 2008). This result demonstrated that Padi6, in addition to Npm2, represents one of the few known mammalian maternal effect genes (MEGs). The potential mechanism by which PADI6 mediates early developmental events is further discussed below.

\section{New findings (A): 1D and 2D proteomics screens identify a new panel of abundant oocyte proteins}

\section{$2 D$ proteomic screen}

The major goal of the above-mentioned work was to further characterize a subset of oocyte-restricted proteins that were identified in the oocyte proteome. In addition to PADI6, cPLA2 $\gamma$, and NPM2, our 2D analysis has also identified one other abundant oocyte-restricted protein: maternal antigen the embryos require (MATER). A summary of all the identified proteins is shown in a reference gel in Fig. 1A, with the oocyte-restricted proteins highlighted (methods for this experiment are described in Wright et al. (2003)). The panels in Fig. 1B and $C$ are enlargements of the relevant regions of the reference gel, and highlight all proteins spots (numbered $1-31)$ that were cored for mass spectroscopic analysis. The identity and further details regarding these molecules are given in Table 1.

Further exploration of the gene annotations of the identified proteins revealed that 9 of the 31 molecules identified in the 2D proteome are HSP/molecular chaperones, with several of these molecules (GRP94, HSP90, HSP70, and BiP) representing some of the most abundant proteins identified in our analysis of the ovulated egg. Given the prominence of these proteins in the ovulated oocyte, one might expect that there would be considerable literature on the function of these molecules during oogenesis and pre-implantation development. However, other than our report on oolemmal HSPs, only a few previous studies have documented the presence of HSPs in oocytes and early embryos (Curci et al. 1991, Manejwala et al. 1991,

Table 1 Proteins identified in a 2D SDS-PAGE proteomic screen of 2850 zona-free metaphase II-arrested mouse oocytes.

\begin{tabular}{|c|c|c|c|c|c|c|}
\hline $\begin{array}{l}\text { Spot } \\
\text { number }\end{array}$ & MGI number & $\begin{array}{c}\text { Theoretical } \\
\text { MW }\end{array}$ & $\begin{array}{c}\text { Theoretical } \\
\text { pl }\end{array}$ & Gene name & Protein name & Function \\
\hline 1 & 2442192 & 162.5 & 5.51 & Eea1 & Early endosome antigen 1 & Endosomal trafficking \\
\hline 2 & 108030 & 72.2 & 4.67 & Hyou1 & Hypoxia up-regulated 1 & ER chaperone \\
\hline 3 & 1345193 & 125.5 & 5.57 & N/rp5 & MATER* & Unknown \\
\hline 4 & 98817 & 90.1 & 4.7 & Hsp90b1 & Grp94 & ER/protein folding \\
\hline 5 & 88261 & 65.0 & 65.0 & Canx & Calnexin & ER/protein folding \\
\hline 6 & 96250 & 84.4 & 4.9 & Hsp90aa1 & Heat shock protein 90 & Protein folding \\
\hline 7 & 95835 & 72.0 & 5.0 & Hspa5 & $\mathrm{BiP}$ & ER chaperone \\
\hline 8,9 & 2655198 & 75.0 & 5.5 & Padi6 & Peptidyl arginine deiminase $6 *$ & Cytoplasmic lattice formation \\
\hline 10 & 88252 & 48.0 & 4.3 & Calr & Calreticulin & ER/protein folding \\
\hline 11 & 97464 & 57.1 & 4.8 & $P 4 h b$ & Protein disulfide isomerase & ER/disulfide bond formation \\
\hline 12 & 99517 & 70 & 5.46 & Hspa1b & Heat shock protein $1 \mathrm{~b}$ & Protein folding \\
\hline 13 & 1196403 & 67.0 & 5.7 & Pla2g4c & $\mathrm{cPLA} 2 \gamma^{*}$ & Cytosolic phospholipase \\
\hline 14 & 109130 & 62.6 & 6.4 & Stip1 & Stress-induced phosphoprotein 1 & Chaperone complex formation \\
\hline 15 & 98869 & 50.2 & 4.9 & Tuba1a & $\alpha$-Tubulin & Cytoskeleton \\
\hline 16 & 1915201 & 50.0 & 4.8 & Tubb6 & $\beta$-Tubulin & Cytoskeleton \\
\hline 17 & 107801 & 56.5 & 5.14 & Atp $5 b$ & ATP synthase, $\beta$-subunit & Mitochondria/ATP synthesis \\
\hline 18,19 & 106014 & 38.4 & 5.17 & Nudc & $\begin{array}{l}\text { Nuclear distribution gene } \\
\text { C homolog }\end{array}$ & Cytoskeleton/spindle formation \\
\hline 20 & 1915205 & 38.8 & 5.11 & Sugt1 & SGT1 & Kinetochore complex formation \\
\hline 21 & 108024 & 33.4 & 5.15 & Rgn & Regucalcin & Others \\
\hline 22 & 1890811 & 23.3 & 5.0 & Npm2 & Nucleophosmin/nucleoplasmin $2 *$ & Others \\
\hline 23,24 & 97831 & 32.8 & 5.27 & Ppa1 & Pyrophosphatase (inorganic) 1 & Others \\
\hline 24 & 1915513 & 38.8 & 5.94 & $P d h b$ & Pyruvate dehydrogenase- $\beta$ & Glycolysis \\
\hline 25 & 96763 & 36.5 & 5.7 & $L d h b$ & Lactate dehydrogenase B & Others \\
\hline 26 & 108109 & 28.3 & 4.8 & Ywhag & $14-3-3 \gamma$ & Others \\
\hline 27 & 109484 & 27.8 & 4.73 & Ywhaz & $14-3-3 \zeta$ & Others \\
\hline 28,29 & 103149 & 24.8 & 5.12 & Uchl1 & Ubiquitin C-terminal hydrolase L1 & Ubiquitination \\
\hline 29 & 2178103 & 23.4 & 5.12 & Arhgdia & Rho GDP dissociation inhibitor- $\alpha$ & Others \\
\hline 30 & 103575 & 18.9 & 4.4 & Skp1a & S-phase kinase-associated protein $1 \mathrm{~A}$ & Ubiquitination \\
\hline 31 & 98351 & 15.9 & 6.0 & Sod1 & Superoxide dismutase 1 , soluble & Antioxidation \\
\hline
\end{tabular}

*Oocyte specific factors. 
Edwards \& Hansen 1997). Interestingly, a recent report found that a major heat shock transcription factor 1 (HSF1), which regulates the transcription of several HSPs, is expressed in murine oocytes. Moreover, the phenotype of Hsf1 knockout (KO) female mice was studied, and it was found that null females produce apparently normal oocytes, but not viable embryos (Metchat et al. 2009). The authors observed that GV breakdown (GVBD) was delayed, there was a partial block to meiosis, and there was an asymmetrical division defect in the null oocytes. Analysis of HSP expression demonstrated that HSP90 (one of the most abundant HSPs in the oocyte, based on our proteomic analysis) was not synthesized in the null oocytes, thus directly implicating at least HSP90, and possibly other HSPs, in oocyte and early embryo function. Given these exciting results, further functional analysis of the role of HSPs in mediating the OET seems warranted.

A number of cytoskeletal proteins were also identified in the $2 \mathrm{D}$ proteome including $\alpha / \beta$-tubulin, NUDC, SGT1, and ARHGDIA. The role of spindle microtubules in oocyte meiosis and early embryonic mitotic cell divisions is well documented; therefore, it was not surprising to find that $\alpha$-tubulin and $\beta$-tubulin are abundantly represented in the oocyte proteome. Interestingly, while the function of NUDC is not well defined, the molecule was originally identified as a microtubuleassociated protein (Lin et al. 2003) that interacts with the key regulators of mitosis such as Polo kinase, and was also found to have chaperone activity in vitro (Faircloth et al. 2009). Regarding Sgt1, somatic cell mutations of this gene were found to severely compromise the organization and function of the mitotic apparatus due to the formation of a highly abnormal spindle (Martins et al. 2009). SGT1 is also known as an HSP90 co-chaperone, and it was recently shown that SGT1/ HSP90 co-chaperone activity is important for kinetochore assembly via stabilization of Polo and also by the activation of another molecule identified in the 2D proteome: SKP1 (Steensgaard et al. 2004). In addition to its role in spindle function, SGT1 is also a subunit of the core kinetochore and SCF ubiquitin ligase complex (Kitagawa et al. 1999). Interestingly, SKP1A and another protein, UCHL1, both identified in our screen, have been found to be involved in ubiquitination, and are also required for the formation of the core kinetochore complex, CBF3, in an HSP90-dependent manner (Stemmann et al. 2002). Taken together, these results suggest the existence of possible links between the identified cytoskeletal, heat shock, and degradation proteins in oocytes.

Other molecules identified in our screen include four molecules that play a role in energy metabolism: ATB5B, PDHB, PPA1, and LDHB. Of the four proteins, LDHB is the only molecule to have been characterized previously in the mammalian oocyte to any degree (Mangia \& Epstein 1975). Other identified molecules that are yet to be described in any detail in oocytes include EEA1 (a protein involved in endosomal trafficking) and SOD1 (an antioxidant). Lastly, we identified regucalcin, which is a calcium-binding protein that plays an important role in calcium signaling via activation of calcium pump enzymes in the plasma membrane of somatic cells (Yamaguchi 2000). This molecule has not been described previously in the oocyte, and may be worth analyzing further given the importance of calcium signaling in egg activation.

While we have mainly focused on further analysis of oocyte-restricted, abundant proteins, we believe that many of the other proteins identified in this screen will also be found to play important roles in oocyte and early embryo development.

\section{$1 D$ proteomic screen}

Our 2D electrophoretic analysis of mouse oocyte proteins was very useful for the identification of oocyte proteins by mass spectrometry and for the partial characterization of these proteins with respect to mass, $\mathrm{pl}$, and relative abundance. However, in an effort to perform a more comprehensive analysis of the oocyte proteome, we next resolved proteins that had been isolated from $\sim 500 \mathrm{MIl}$-arrested eggs on a 1D SDSPAGE gel. The gel was then stained with Coomassie, and entire lanes were cropped from top to bottom into 52 gel slices (Fig. 2). The gel slices were then digested with trypsin, and peptide sequences were identified by liquid chromatography-mass spectrometry using a Finnigan LCQ ion trap mass spectrometer (more detail of the methods can be found in (Coonrod et al. 2006)). The data were then analyzed by database searching using the Seaquest algorithm. Compared with 2D electrophoresis, this approach was somewhat limited in that we could not determine the $\mathrm{pl}$ of the proteins; nor could we determine their relative abundance, since the bands often contained peptides from several different proteins. However, a major advantage of our 1D proteomic analysis over our 2D screens was that by concentrating the proteins into single lanes, we were able to identify over 150 proteins with just 500 oocytes as input. A complete list of proteins that were identified in this screen is given in Supplementary Table 1, see section on supplementary data given at the end of this article.

Following identification, we utilized Pubmed information in the NCBI database and, where possible, the Gene Ontogeny information in the Mouse Genome Informatics browser at the Jackson Laboratory (http:// www.informatics.jax.org/) to classify the proteins according to the molecular function. In some cases, their molecular function was not known, so we classified these proteins according to their cellular localization (i.e. mitochondria and cytoskeleton). A summary of the different functional categories along with the percentage of proteins that fell into each of the categories is shown in 


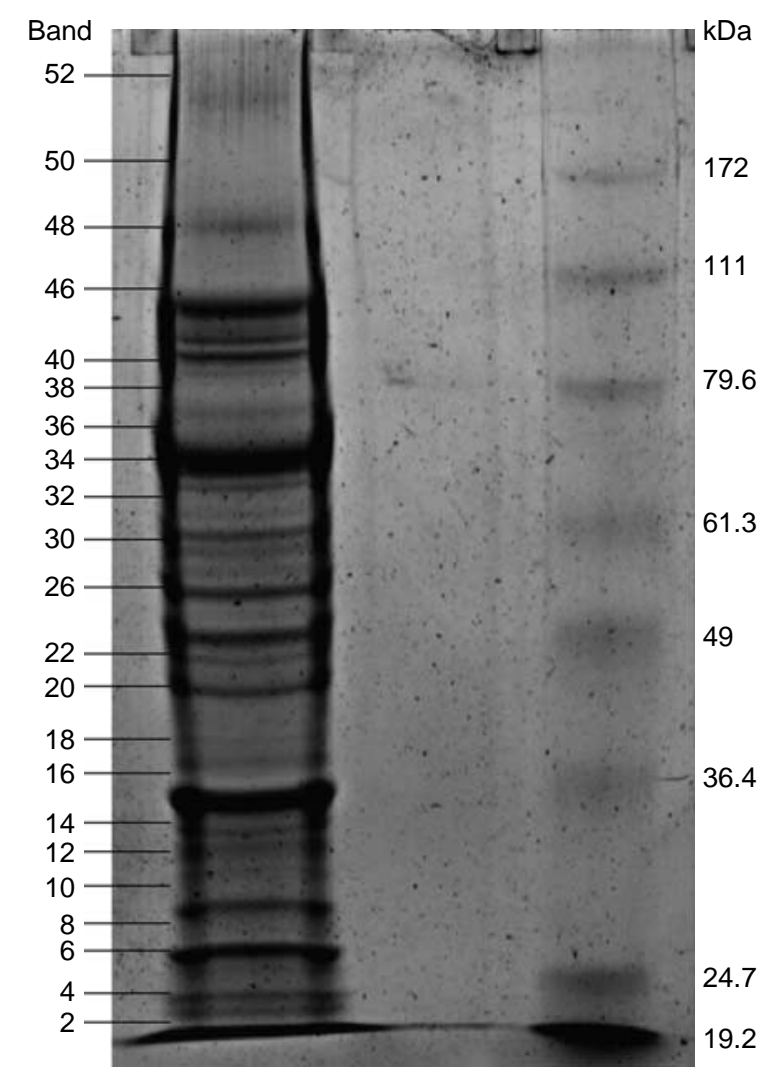

Figure 2 Coomassie-stained 1D SDS-PAGE gel of metaphase II-arrested mouse oocytes. In order to perform a comprehensive proteomic screen, proteins were isolated from 500 metaphase II-arrested mouse oocytes, resolved on a 1D SDS-PAGE gel, and visualized by Coomasie staining. This gel was then separated into 52 gel slices that were individually analyzed by mass spectrometry. The proteins identified by this method are listed by functional group in Supplementary Table 1 .

the pie chart in Fig. 3. Results show that the most highly represented categories include metabolism (24\%), oxidation/reduction (redox, 10\%), protein transport $(12 \%)$, chaperone $(11 \%)$, and ubiquitination/protein degradation ( $9 \%$ ). Given that the ovulated mammalian oocyte must largely 'fend for itself' prior to implantation, the finding that metabolism, redox, and mitochondriaassociated proteins are highly represented is not surprising. Furthermore, the oocyte is a relatively large cell and is known to have a high secretory capacity, thus, the finding that $12 \%$ of the identified proteins appear to be involved in protein transport is also understandable. The observation that $11 \%$ of the identified proteins have chaperone activity is also not surprising given our finding that HSPs are some of the most highly represented proteins in the ovulated egg. The detection of $9 \%$ of the proteins that fall into the ubiquitination and protein degradation category fits well with previous studies showing that many proteins appear to be degraded shortly after fertilization (Josefsberg et al. 2000). This also correlates well with the fact that oocyte gene expression is predominantly regulated on a post-transcriptional level. Finally, comparison of our 1D screen to EST databases shows that the relative abundance of housekeeping gene products is low in oocytes compared with somatic cells or even two-cell stage embryos (Evsikov et al. 2006), supporting the hypothesis that the oocyte appears to require a specific array of factors to mediate the OET.

\section{New findings (B): our oocyte proteomics database identifies several bona fide MEGs and putative MEGs}

A maternal effect occurs when the phenotype of the progeny is determined by the genotype of the mother. Therefore, a MEG can be defined as a gene whose product (either mRNA or protein) is synthesized in the oocyte and plays an essential role in early development. Our proteomic screens identified numerous oocyte and early embryo-restricted genes (see Tables 1 and 2), some of which appear to be bona fide MEGs, while others represent potential MEGs. We highlight and discuss these factors (see Table 2) below. All the proteins discussed below have also been identified in another recent proteomics screen (Zhang et al. 2009).

\section{Bona fide maternal effect genes}

\section{DNA methyltransferase (cytosine-5) 10 (DNMT1O, gene: Dnmt1)}

The DNMT1O protein arises from alternative splicing of the Dnmt1 gene in which there is an oocyte-specific exon. Translation of this unique transcript results in a smaller form of DNMT1 than the protein found in somatic cells (Mertineit et al. 1998). DNMT1O expression begins during oocyte growth, where it can be found in the nucleus and cytoplasm of the oocyte, but by the time the oocyte reaches the GV or MII stage, the protein localizes solely to the cytoplasm. Interestingly, DNMT1O remains cytoplasmic during the early cleavage stages except during the eight-cell stage where it can be transiently detected in the nucleus (Howell et al. 2001). When Dnmt1o KO mice were generated, male and female homozygotes appeared grossly normal. However, whereas the males were fertile, the females were found to be infertile, giving rise to embryos that died between E14 and E21 (Howell et al. 2001), and making Dnmt1 a bona fide MEG. DNMT1O was found to be necessary for DNA methylation maintenance during the fourth $\mathrm{S}$ phase of embryonic development in order to ensure correct inheritance of parental epigenetic imprints (Cirio et al. 2008).

\section{FILIA (gene: 2410004A20Rik)}

FILIA was originally described as a protein whose expression was dramatically decreased in Mater $\mathrm{KO}$ oocytes. It was shown to interact and form a complex with MATER, and to have a very similar expression 


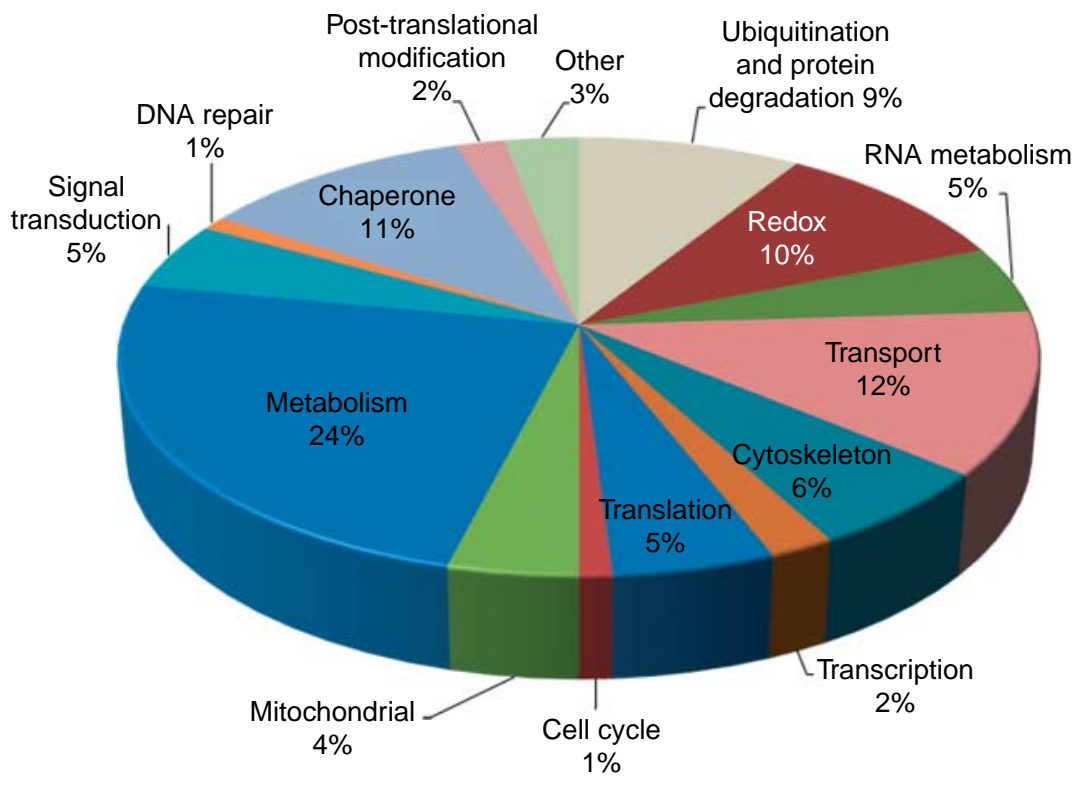

Figure 3 Functional classification of the most abundant proteins in the metaphase II-arrested mouse oocyte. One hundred and eighty-five unique proteins were identified in our $1 \mathrm{D}$ proteomic screen (gel shown in Fig. 2) of metaphase II-arrested mouse oocytes. The percentage of proteins that have been shown or predicted (based on sequence homology) to function in various cell processes or compartments are graphed here. The corresponding proteins are listed in Supplementary Table 1. pattern during oocyte growth and embryogenesis, with the protein levels dropping off at the blastocyst stage. The mRNA can be found in the growing oocyte, but it is degraded during meiotic maturation (Ohsugi et al. 2008). Shortly thereafter, the subcortical maternal complex (SCMC) was observed and characterized, and both FILIA and MATER were shown to be part of this complex (Li et al. 2008). When Filia KO mice were generated, the authors described a $50 \%$ decrease in fertility, with litter sizes being half that of wild-type (WT) or heterozygous animals. This decrease was demonstrated to be due to impaired pre-implantation development, with the absence of Filia causing a delay in cell cycle progression. Furthermore, FILIA was shown to be involved in proper spindle formation as well as in the spindle assembly checkpoint (Zheng \& Dean 2009).

\section{Factor located in oocytes permitting embryonic development (gene: Ooep)}

The factor located in oocytes permitting embryonic development (FLOPED) protein (also known as MOEP19) was first characterized from an oocyte 2D proteomic screen performed by Herr et al. (2008). The authors cloned and characterized this protein, which contains a eukaryotic type $\mathrm{KH}$ domain (typical of the $\mathrm{KH}$ domain type I superfamily of RNA-binding proteins), and demonstrated that it can indeed bind ribonucleotide

Table 2 Bona fide and putative maternal effect genes (MEGs) identified in proteomic screens.

\begin{tabular}{|c|c|c|c|}
\hline & Knockout phenotype & Localization within the oocyte/embryo & Association with MES \\
\hline \multicolumn{4}{|l|}{ Bona fide MEGs } \\
\hline Dnmt1 (DNMT1O) & Death at E14 to E21 & $\begin{array}{l}\text { Cytoplasmic with brief nuclear localization } \\
\text { during the eight-cell stage }\end{array}$ & CPL? MVA? SCMC? \\
\hline 2410004A20Rik (FILIA) & $50 \%$ Decrease in female fertility & Cortex & SCMC \\
\hline Ооер (FLOPED) & Two- to four-cell embryo arrest & Cortex & SCMC \\
\hline Nlrp5 (MATER) & Two-cell embryo arrest & Cortex & SCMC \\
\hline $\mathrm{Npm} 2$ & $\begin{array}{l}70 \% \text { decrease in female fertility, } 95 \% \text { of } \\
\text { embryos arrest before blastocyst stage }\end{array}$ & $\begin{array}{l}\text { Nuclear, with transient cortical staining } \\
\text { during the MII oocyte stage }\end{array}$ & SCMC? \\
\hline Oas1d & $\begin{array}{l}30 \% \text { Decrease in female fertility, } 40 \% \text { of } \\
\text { embryos arrest by eight-cell stage }\end{array}$ & Cytoplasm and cortex & CPL? MVA? SCMC? \\
\hline Padi6 & Two-cell embryo arrest & Cytoplasm and cortex & CPL SCMC? \\
\hline \multicolumn{4}{|l|}{ Putative MEGs } \\
\hline Pla2g4c (cPLA2 $\gamma)$ & NA & Cytoplasm and cortex & Spindle MVA? SCMC? \\
\hline Dppa5a & $\begin{array}{l}\text { Normal fertility due to possible redun- } \\
\text { dancy with } \mathrm{KH} \text { family members }\end{array}$ & Cytoplasm & CPL? MVA? \\
\hline Nlrp14 & NA & Cytoplasm & CPL? MVA? \\
\hline Spin1 & NA & Cytoplasm & Spindle 3 CPL? MVA? \\
\hline Tle6 & NA & Cortex & SCMC \\
\hline
\end{tabular}

MES, maternal effect structure; CPL, cytoplasmic lattice; SCMC, subcortical maternal complex; MVA, multivesicular aggregate; NA, not available. Putative associations indicated by '?'. 
homopolymers. They also performed immunofluorescence experiments showing that FLOPED stains the cortical region of the oocyte and early embryo, and that staining was not detected after the blastocyst stage. Floped $\mathrm{KO}$ mice were generated shortly thereafter, and the phenotype was described as a two-cell stage developmental arrest, with a few rare embryos progressing to the fourcell stage. However, no embryos were detected beyond this stage (Li et al. 2008). FLOPED was also shown to be able to interact with MATER, transducin-like enhancer of split 6 (TLE6), and FILIA as part of the SCMC.

\section{Maternal antigen the embryos require (gene: NIrp5)}

MATER is a highly abundant mouse oocyte protein (Fig. 1) that is essential for embryonic development beyond the two-cell stage. MATER was originally identified as an oocyte-specific antigen in a mouse model of autoimmune premature ovarian failure (Tong \& Nelson 1999). MATER demonstrates an expression and subcellular expression profile that is similar to that of PADI6. Also, similar to the phenotype of Padi6-null animals, Mater-null females exhibit normal oogenesis, ovarian development, oocyte maturation, ovulation, and fertilization. However, embryos derived from Mater-null females undergo a developmental block at the two-cell stage, and fail to exhibit normal embryonic genome activation (Tong et al. 2000a, 2000b). The molecular function of MATER is still unclear; however, it contains a conserved leucine-rich domain at the carboxyl terminus and an ATP-/GTP-binding domain (P-loop; Tong et al. 2002). It has been suggested that MATER may be involved in cellular signaling (Tong et al. 2002), and, as mentioned above, it has been demonstrated that MATER localizes to the oocyte SCMC (Li et al. 2008), which is further discussed below.

\section{Nucleoplasmin 2 (gene: Npm2)}

NPM2 has been discussed in the previous section.

\section{$2^{\prime}-5^{\prime}$ oligoadenylate synthetase $1 d$ (OAS1D, gene: Oas1d)}

OAS1D belongs to a family of proteins whose role is to bind to and aid in the degradation of double-stranded RNA. There are eight homologs of the Oas1 gene in mice, labeled ' $a$ ' to ' $h$ ', which, along with Oas2 and Oas3, form a gene cluster on chromosome 5 (Eskildsen et al. 2002, Mashimo et al. 2003). OAS1D is an oocytespecific protein, and its mRNA is expressed solely in growing oocytes. OAS1D protein can still be detected in early embryos, but its levels are drastically reduced after the first mitotic division. Mice lacking the Oas1d gene are subfertile and produce only about half as many oocytes as WT mice. Of embryos derived from these null oocytes, only $60 \%$ survive to the eight-cell stage. When the animals are treated with a synthetic dsRNA, this number drops dramatically to about $35 \%$ of fertilized oocytes passing the eight-cell stage (Yan et al. 2005). These studies indicate that even though (like Filia) defects in the Oas1d gene are not fully penetrant, it is still important for early development and can still be classified as a bone fide MEG.

\section{Peptidylarginine deiminase 6 (gene: Padi6)}

PADI6 has been discussed in the previous section.

\section{Putative maternal effect genes}

Cytosolic phospholipase A2 $\gamma$ (gene: Pla2g4C)

CPLA2 $\gamma$ has been discussed in the previous section.

Developmental pluripotency-associated 5A (DPPA5A, gene: Dppa5a)

Developmental pluripotency-associated 5A (DPPA5A) has been studied mainly in ES cells, where it is also known as embryonal stem cell-specific gene 1 (ESG1), $\mathrm{PH} 34$, or ECAT2. Western et al. showed that DPPA5A is expressed in pluripotent cells of the pre-implantation embryo but is then specifically restricted to and maintained only in germ cells until after sex determination. The authors also showed that this protein is lost in human embryonal carcinoma cells, and therefore suggested that DPPA5A plays a role in the regulation of pluripotency and primordial germ cell development (Western et al. 2005). Another group mapped the Dppa5a gene to chromosome 9 in mice, but also found that there are several pseudogenes, some of which have significant overlap with the Dppa5a gene. They then produced the Dppa5a KO ES cells and mice. The null mice were shown to be phenotypically normal with normal fertility; therefore, they judged DPPA5A to be dispensable for normal mouse development and germ cell formation (Amano et al. 2006). The same group went on to further characterize the expression of DPPA5A in mice, and found that the Dppa5a mRNA is readily detected in the cytoplasm of GV oocytes in the ovary, in ovulated MII-stage oocytes, and the blastomeres of onecell, four-cell, eight-cell, morula, and blastocyst stages. As for the protein, it can also be seen in the same stages as the mRNA, but remains confined to the inner cell mass of blastocysts. Finally, they further demonstrated that the $\mathrm{KH}$ domain of the DPPA5A confers upon it the ability to bind RNA (Tanaka et al. 2006). Although Dppa5a has all the hallmarks of being a MEG, the KO mice have no gross phenotype. It is possible that the normal fertility in these mice could be due to functional redundancy either with the various pseudogenes they identified or with other closely related $\mathrm{KH}$ domain proteins such as FLOPED (discussed above) or Stella, a MEG not detected in our screen (Payer et al. 2003). Accordingly, it would be interesting to observe the phenotype of crosses between Dppa5a- and Floped- or Stella-null mice. 
NLR family, pyrin domain-containing 14 (NLRP14, gene: Nlrp14)

NLRP14 (also called NALP iota or NALP14) is part of a family of homologous genes that are localized in three clusters on mouse chromosome 7. Interestingly, MATER (also called NLRP5 or NALP5) is part of this family. NLRP14 is the only member of this family that does not contain a pyrin domain. Expression of Nlrp14 mRNA was shown to be restricted to the ovary, and more detailed analysis revealed that the mRNA level is high in GV and MII oocytes, but begins to decrease after fertilization and drops off after the two- to four-cell stage. When fertilized eggs were injected with siRNA against NIrp14 mRNA, a third of the embryos arrested at the two- to four-cell stage, which is reminiscent of other MEG depletion phenotypes mentioned above (Hamatani et al. 2004b). Another group determined that the expression of NLRP14 is detectable in early two-cell embryos, but is not seen in late two-cell embryos (Evsikov et al. 2006), which could implicate NLRP14 in the OET. Finally, FIGLA, a germline-specific transcription factor, was shown to be responsible for the expression of Nlrp14 in perinatal ovaries (Joshi etal. 2007). Although there are no NIrp14 KO mice reported to date, the existing data make NIrp14 a likely candidate MEG.

\section{Spindlin (gene: Spin1)}

Spindlin was originally characterized as a stage-specific embryonic protein. Expression of Spin1 mRNA is restricted to oocytes in the ovary, and the protein can be detected in the cytoplasm of growing oocytes, with maximal levels being attained in the fully grown oocyte. Moreover, spindlin is seen co-localizing with the spindle apparatus, which is most striking in ovulated oocytes (Oh et al. 1997). The same investigators later showed that spindlin is phosphorylated by the MOS/MAP kinase pathway, and that this phosphorylation is necessary for its association with the spindle (Oh et al. 1998). Recently, it was shown that the overexpression of spindlin in NIH3T3 cells causes multinucleation, aneuploidy, and eventually leads to apoptosis demonstrating the importance of spindlin for correct chromosome segregation (Yuan et al. 2007). Given these data, it is possible that spindlin $\mathrm{KO}$ mice would be inviable; however, the phenotype resulting from the depletion of spindlin may not be as severe as its overexpression. Also, it is possible that it may function differently in meiosis than in mitosis.

\section{Transducin-like enhancer of split 6 (gene: Tle6)}

TLE6 belongs to the Groucho/Tle superfamily of transcriptional co-repressors that play critical roles in a range of developmental processes (Bajoghli 2007), and has only recently been described in oocytes and early embryos. TLE6 transcripts accumulate in growing oocytes, but are quickly degraded after oocyte maturation, with virtually no detectable mRNA in twocell embryos. The protein, however, first appears during oocyte growth and persists up to the blastocyst stage. TLE6 is yet another partner in the SCMC, along with FLOPED, MATER and FILIA. The interaction of TLE6 with the other members of the SCMC is believed to be conferred via its WD repeats (Li et al. 2008). The exact role of TLE6 in the SCMC or in oocytes remains to be defined, and to date, no $\mathrm{KO}$ mice have been reported, though it seems likely that the phenotype would be similar to the one observed in MATER, FILIA, or FLOPED $\mathrm{KO}$ mice.

\section{Discussion}

\section{Oocyte proteomic studies indicate that MEG products are highly represented in the mature egg}

To date, our proteomic studies have provided significant molecular insight into the processes of oocyte maturation, fertilization, and pre-implantation development. Additionally, our studies have shown that some of the more abundant proteins in the mature MII-arrested oocyte are not ubiquitous 'housekeeping' genes, as might be expected, but instead are MEGs whose expression appears to be limited to the oocyte. Furthermore, based on older metabolic labeling experiments and more recent expression analysis, it seems likely that synthesis of many of these proteins begins during oocyte growth, and that these factors are then stored in the egg for future use following fertilization. If this prediction is correct, then many of the abundant proteins shown on the 2D gel in Fig. 1 may actually represent stored maternal proteins that function in early embryonic events. This hypothesis is also supported by new findings showing an early embryonic developmental arrest phenotype for mice that carry mutated versions of genes encoding seven of the molecules identified in our proteomics screens (see Table 2): DNMT1O (Howell et al. 2001), FILIA (Zheng \& Dean 2009), FLOPED (Li et al. 2008), MATER (Tong et al. 2000a), NPM2 (Burns et al. 2003), OAS1D (Yan et al. 2005), and PADI6 (Esposito et al. 2007). To date, most functional analyses of oocyte proteins have been limited to proteins that are primarily expressed in the oocyte and give rise to female infertility. However, it seems likely that functional analysis of other abundant non-oocyte-restricted proteins in a developmental context would also be highly productive. The observation that Hsf1, which regulates the expression of most of the HSPs identified in this study, functions as a MEG supports this hypothesis. A number of previously characterized MEGs were actually not observed in our proteomic screens including Brahma-related gene 1 (Brg1; Bultman et al. 2006), Hsf1 (Christians et al. 2000), zygote arrest 1 (Zar1; Wu et al. 2003), Stella (Dppa3; Payer et al. 2003), CCCTC-binding factor (Ctcf; Wan et al. 2008), postmeiotic segregation increased 2 
(Pms2; Gurtu et al. 2002), and basonuclin (Bnc1; Ma et al. 2006). It is interesting to note that most of the MEGs that were not detected in our screen are involved in transcription. However, this observation is not too surprising given that transcription factors are commonly expressed at low levels, and therefore likely below the detection threshold. This is supported by the observation that while we did not identify Hsf1 itself, several of its target genes were detected.

\section{Are some highly represented proteins in the MII-arrested egg associated with 'maternal effect structures'?}

One route for gaining insight into proteins that are highly represented in the oocyte proteome is to determine what organelles or structures these molecules are associated with in the oocyte. If, as we have predicted, many or most of these abundant proteins function after fertilization, then another question to be answered is: by what mechanism are these proteins stored during oocyte growth? Are they floating freely in the cytosol, or are they anchored to, or part of, large macromolecular structures? If the latter hypothesis is correct, then it is possible that the repertoire of proteins seen on our 2D oocyte protein gel could primarily represent proteins that are associated with several large macromolecular storage structures that form during oocyte growth, and whose function, at least in part, is to facilitate early embryonic development. Remarkably, of the MEG proteins characterized to date, several of them appear to localize to a subset of poorly characterized oocytespecific features that may function as 'maternal effect structures' (MESs; see Fig. 4 and Table 2). Based on our findings and on the findings of others, we propose that that candidate MESs include MVAs, microtubule-organizing centers (MTOCs), the meiotic spindle, the cytoplasmic lattices (CPLs), and the SCMC. A discussion of these maternal structures follows, and a diagram depicting these putative MESs is shown in Fig. 4.

\section{Multivesicular aggregates and microtubule-organizing centers}

The oocyte MVAs are complex structures that contain aggregates of different types of membrane-bound
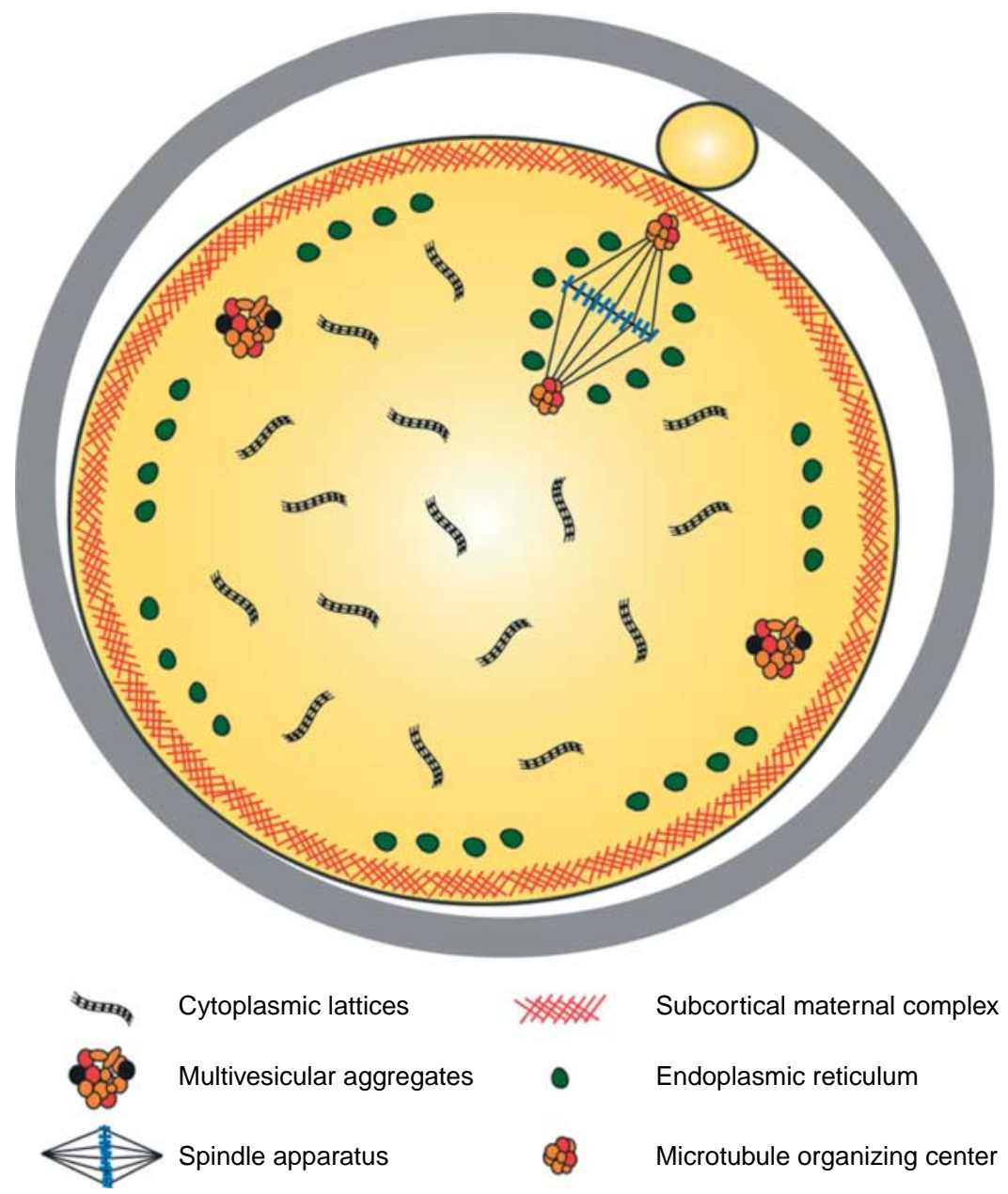

Figure 4 Putative maternal effect structures of the metaphase II-arrested mouse oocyte. Structures that we have termed 'maternal effect structures' or 'MESs' that we have predicted will be found to play a central role in mediating the oocyte-to-embryo transition are illustrated here. Furthermore, as outlined in Table 2, we have also predicted that many of the oocyteabundant proteins identified in our proteomic screens will be found to localize to and play important roles in MES function. 
vesicles, electron-dense particles, and cytoskeletal proteins such as $\gamma$-tubulin (Calarco 2000). Interestingly, there are only two very large $(\sim 10 \mu \mathrm{m})$ MVAs, which localize to the oocyte cortex in the fully grown GV-staged oocyte, and these structures begin to migrate toward the nucleus during maturation. The MVAs then fragment into smaller pieces and surround the nuclear envelope prior to GVBD. Next, these smaller structures appear to give rise to another unique structure: the oocyte MTOC, which functions to nucleate microtubules during spindle pole formation after GVBD (Calarco 2000). Interestingly, our analysis of cPLA2 $\gamma$ found that this oocyte-restricted molecule co-localized with $\gamma$-tubulin at large foci near the oocyte cortex, and these cPLA2 $\gamma / \gamma$-tubulin aggregates were seen to break into smaller foci during oocyte maturation, eventually surrounding the nucleus prior to GVBD and then localizing to the spindle poles in fully mature oocytes (Vitale et al. 2005). Given the similar migratory properties and the fact that both MVAs and CPLA2 $\gamma$ appear to associate with $\gamma$-tubulin, it seems likely that CPLA2 $\gamma$ represents a component of the MVAs and possibly MTOCs. While the fate of the MVAs following fertilization is not known, previous reports have predicted that these structures may function as storage organelles for centrosomal components such as $\gamma$-tubulin and pericentrin, which then facilitate early mitotic divisions (Calarco 2000). If CPLA2 $\gamma$ is, in fact, associated with MVAs, our western blot and immunofluorescence analyses showing that the CPLA2 $\gamma$ protein persists until the four- to eight-cell stage of development support the hypothesis that the MVAs persist throughout early cleavage divisions. Given these observations, we believe that the MVAs represent a strong candidate MES, and that further analysis of $\mathrm{CPLA} 2 \gamma$ and the MVAs will likely provide insight into the mechanisms by which maternal factors facilitate early stages of mitosis.

\section{Meiotic spindle}

Meiosis is a complex process that results in the formation of haploid male and female germ cells. In the oocyte, meiotic maturation is the final stage of meiosis, in which the homologous chromosomes are separated by a cytoskeletal structure called the meiotic spindle. As mentioned earlier, during GVBD, microtubules nucleate and begin to grow from MTOCs and interact with chromosomes to rapidly form a bi-polar spindle. Following spindle assembly, chromosomes then align at the spindle equator to form the metaphase plate and enter MIl-arrest (Rodrigues et al. 2008). This arrest is maintained by the presence of a cytostatic factor (which, in mice, is most likely c-mos), which functions by regulating the MAP kinase pathway (Brunet \& Maro 2005). In order to maintain the correct ploidy, chromosome segregation needs to be equal; therefore, this process is highly regulated by spindle assembly checkpoint proteins. Calcium transients are initiated following fertilization, and these transients activate (possibly via CAMKII) the E3 ligase-containing anaphase-promoting complex/cyclosome. This complex begins to degrade the key cell cycle regulators such as cyclin B1 by ubiquitination and proteolysis, thus facilitating anaphase initiation, chromosome segregation, and polar body extrusion (Jones 2005). The molecular underpinnings of the mammalian meiotic spindle complex remain, in large part, to be resolved. With respect to meiotic centrosomes, numerous cell cycle regulators localize to this structure, and the centrosomes are also thought to represent the maternal contribution of materials that are utilized for mitosis in the early embryo (Carabatsos et al. 2000). Given these observations, it seems possible that many of the cytoskeletal, cell cycle, and protein degradation factors identified in our 2D and 1D proteomic screens will be found to localize to this germ cell-restricted structure. Additionally, as noted previously, many of the HSPs that we identified in the oocyte proteome are thought to localize to the ER in somatic cells via their KDEL C-terminus-anchoring motif. Interestingly, a recent report found that during oocyte maturation, the ER first envelops and then invades the meiotic spindle apparatus, thus placing the ER in juxtaposition with the meiotic spindle (FitzHarris et al. 2007). Taken together, these results now implicate ER-associated HSPs in meiotic spindle function. Moreover, these results raise the possibility that some of the HSPs identified in our screen might localize to, and interact with, the meiotic spindle apparatus, suggesting that certain components of the meiotic spindle may function as a MES.

\section{Cytoplasmic lattices}

One of the most abundant intracellular oocyte and early embryo-restricted structures visible by EM is the CPLs (also called the cytoplasmic sheets). The CPLs consist of 5-7 granular fibers intertwined with bulbous repeating units of 20-25 nm (Capco et al. 1993). Analysis of the ontogeny of the lattices found that they first appear in the cytoplasm when oocytes begin to develop and dramatically increase in number throughout growth (Wassarman \& Josefowicz 1978). Early descriptive accounts in the literature suggested that the lattices function as some type of yolk; however, there is no evidence that these structures contain lipids (Weakley 1969). Other investigators explored the possible function of the lattices using biochemical analysis, and concluded that they likely contain either ribosomes or ribosomal components (Bachvarova et al. 1981, Sternlicht \& Schultz 1981). We first became interested in the lattices when we performed immunoelectron microscopy on mouse oocytes and found that PADI6 localized to this structure (Wright et al. 2003). In order to begin investigating the relationship between PADI6 and the CPLs, 
we investigated the effects of loss of PADI6 on CPL structure using Padi6-null mice. We found that the oocyte CPLs are not observed at any stage of oocyte development in Padi6 KO females, indicating that PADI6 is required for nucleation and maintenance of this structure in oocytes (Yurttas et al. 2008). We also tested the hypothesis that the CPLs contain ribosomes using our Padi6-null mouse model. Based on the unique solubility profile of rRNA in oocytes versus somatic cells, it had been suggested previously that oocyte ribosomes are associated with a large supramolecular complex, most likely the CPLs. We found that ribosomal component solubility was greatly increased in null oocytes, and predicted that this increased solubility is due to the fact that ribosomes are no longer associated with the CPLs. Previous investigators had also predicted that the CPLassociated ribosomes were likely stored in the oocyte for later use by the early embryo to facilitate embryonic translation. We further tested this hypothesis, and found that while nascent protein translation was not dramatically affected in Padi6-null oocytes, protein synthesis was reduced in Padi6-null two-cell embryos before their arrest (Yurttas et al. 2008). Taken together, our analysis of the CPLs in Padi6-null oocytes and early embryos further strengthened the hypothesis that the oocyte CPLs do contain ribosomal components, and that these components facilitate protein translation in early embryos prior to the activation of the embryonic genome. Our findings that PADI6 is required for CPL formation and maintenance and that the developmental arrest of Padi6null mice occurs at the two-cell stage suggest that the CPLs do not play an essential role in oocyte function. Rather, CPLs, or at least factors contained in these structures, are required for early developmental events. These findings support the hypothesis that the oocyte CPLs represent another MES. We are currently using biochemical and proteomic approaches to further elucidate the molecular nature of the CPLs, and to predict that these structures will also be found to store a number of other MEG products that facilitate early embryonic development.

\section{The subcortical maternal complex}

As mentioned earlier, a number of oocyte-abundant proteins that we have identified in the mouse oocyte proteome such as MATER, NPM2, and FLOPED have been analyzed by other investigators using mutant mouse lines. Results show that, as with PADI6, these molecules do not play an essential role in oogenesis, but instead are required for early embryonic development. Interestingly, Li et al. (2008) found by confocal microscopy that both MATER and FLOPED localize to a region just below the oocyte cortex in oocytes, and that this region also contains two other oocyte-restricted proteins, FILIA and TLE6. The two main structures that can be visualized at the oocyte cortex by EM are cortical granules and ER vesicles. However, the confocal immunflourescence staining pattern for these proteins suggested that they are not associated with these organelles. Moreover, while these proteins partially co-localize with subcortical microfilament proteins, the staining pattern extends deeper into the cytoplasm than into the microfilaments and does not localize to apposed (cell-cell contact) regions of blastomeres throughout preimplantation development. These results led the authors to propose the existence of a SCMC, and we predict that this complex represents another MES. We found by immunofluorescence that NPM2, which primarily localizes to the nucleus at interphase, is targeted to the oocyte cortex following GVBD (Vitale et al. 2007). Therefore, it will be interesting to investigate whether NPM2 co-localizes with the SCMC proteins in the MII-arrested egg. Additionally, while our immuno-EM analysis of PADI6 primarily localized this molecule to the CPLs, our confocal immunoanalysis found that a significant amount of PADI6 also apparently localizes to the MII-arrested egg cortex, and that this localization pattern becomes more pronounced in the two-cell embryo. These findings suggest that a molecular crosstalk may exist between the CPLs and the SCMC, and experiments are currently being carried out to test this hypothesis.

\section{Conclusion}

In conclusion, we believe our proteomic analysis of the ovulated mouse oocyte is yielding significant insight into oocyte and early embryo function. However, to date, we have only characterized a fraction of the proteins identified in our screen, and, given our findings, we believe that many of the yet-to-be-characterized proteins will likely be found to be critical players in the OET. Therefore, additional functional analysis of these molecules through the use of mutant mouse models seems warranted. In particular, it will be of interest to determine how many of these proteins will be found to localize to, and be required for the formation of MESs.

\section{Supplementary data}

This is linked to the online version of the paper at http://dx.doi. org/10.1530/REP-09-0538.

\section{Declaration of interest}

The authors declare that there is no conflict of interest that could be perceived as prejudicing the impartiality of the research reported.

\section{Funding}

This work was supported by the National Institutes of Health (NIH 2RO1 HD38353 and NIH RO3 HD522241). 


\section{References}

Albee AJ \& Wiese C 2008 Xenopus TACC3/Maskin is not required for microtubule stability but is required for anchoring microtubules at the centrosome. Molecular Biology of the Cell 193347.

Alfieri JA, Martin AD, Takeda J, Kondoh G, Myles DG \& Primakoff P 2003 Infertility in female mice with an oocyte-specific knockout of GPI-anchored proteins. Journal of Cell Science 116 2149-2155.

Altmeyer A, Maki RG, Feldweg AM, Heike M, Protopopov VP, Masur SK \& Srivastava PK 1996 Tumor-specific cell surface expression of the-KDEL containing, endoplasmic reticular heat shock protein gp96. International Journal of Cancer 69 340-349.

Amano H, Itakura K, Maruyama M, Ichisaka T, Nakagawa M \& Yamanaka S 2006 Identification and targeted disruption of the mouse gene encoding ESG1 (PH34/ECAT2/DPPA5). BMC Developmental Biology 611.

Bachvarova R 1981 Synthesis, turnover, and stability of heterogeneous RNA in growing mouse oocytes. Developmental Biology 86 384-392.

Bachvarova R, De Leon V \& Spiegelman I 1981 Mouse egg ribosomes: evidence for storage in lattices. Journal of Embryology and Experimental Morphology 62 153-164.

Bajoghli B 2007 Evolution of the Groucho/Tle gene family: gene organization and duplication events. Development Genes and Evolution 217 613-618.

Brown JK, Knight PA, Thornton EM, Pate JA, Coonrod S, Miller HR \& Pemberton AD 2008 Trichinella spiralis induces de novo expression of group IVC phospholipase A2 in the intestinal epithelium. International Journal for Parasitology 38 143-147.

Brunet S \& Maro B 2005 Cytoskeleton and cell cycle control during meiotic maturation of the mouse oocyte: integrating time and space. Reproduction 130801.

Bultman SJ, Gebuhr TC, Pan H, Svoboda P, Schultz RM \& Magnuson T 2006 Maternal BRG1 regulates zygotic genome activation in the mouse. Genes and Development 20 1744-1754.

Burns KH, Viveiros MM, Ren Y, Wang P, DeMayo FJ, Frail DE, Eppig JJ \& Matzuk MM 2003 Roles of NPM2 in chromatin and nucleolar organization in oocytes and embryos. Science 300 633-636.

Calarco PG 2000 Centrosome precursors in the acentriolar mouse oocyte. Microscopy Research and Technique 49 428-434.

Calvert ME, Digilio LC, Herr JC \& Coonrod SA 2003 Oolemmal proteomics: identification of highly abundant heat shock proteins and molecular chaperones in the mature mouse egg and their localization on the plasma membrane. Reproductive Biology and Endocrinology 127.

Capco DG, Gallicano GI, McGaughey RW, Downing KH \& Larabell CA 1993 Cytoskeletal sheets of mammalian eggs and embryos: a lattice-like network of intermediate filaments. Cell Motility and the Cytoskeleton $\mathbf{2 4}$ 85-99.

Carabatsos MJ, Combelles CMH, Messinger SM \& Albertini DF 2000 Sorting and reorganization of centrosomes during oocyte maturation in the mouse. Microscopy Research and Technique 49 435-444.

Christians E, Davis AA, Thomas SD \& Benjamin IJ 2000 Maternal effect of Hsf1 on reproductive success. Nature 407 693-694.

Cirio MC, Martel J, Mann M, Toppings M, Bartolomei M, Trasler J \& Chaillet JR 2008 DNA methyltransferase 1o functions during preimplantation development to preclude a profound level of epigenetic variation. Developmental Biology 324 139-150.

Coonrod SA, Naaby-Hansen S, Shetty J, Shibahara H, Chen M, White JM \& Herr JC 1999 Treatment of mouse oocytes with PI-PLC releases 70-kDa (pl 5) and 35- to 45-kDa (pl 5.5) protein clusters from the egg surface and inhibits sperm-oolemma binding and fusion. Developmental Biology 207 334-349.

Coonrod S, Vitale A, Duan C, Bristol-Gould S, Herr J \& Goldberg E 2006 Testis-specific lactate dehydrogenase (LDH-C4; Ldh3) in murine oocytes and preimplantation embryos. Journal of Andrology 27 502-509.

Curci A, Bevilacqua A, Fiorenza MT \& Mangia F 1991 Developmental regulation of heat-shock response in mouse oogenesis: identification of differentially responsive oocyte classes during Graafian follicle development* 1. Developmental Biology 144 362-368.

Edwards JL \& Hansen PJ 1997 Differential responses of bovine oocytes and preimplantation embryos to heat shock. Molecular Reproduction and Development 46 138-145.
Eng JK, McCormack AL \& Yates JR 1994 An approach to correlate tandem mass spectral data of peptides with amino acid sequences in a protein database. Journal of the American Society for Mass Spectrometry $\mathbf{5}$ 976-989.

Eskildsen S, Hartmann R, Kjeldgaard NO \& Justesen J 2002 Gene structure of the murine $2^{\prime}-5^{\prime}$-oligoadenylate synthetase family. Cellular and Molecular Life Sciences 59 1212-1222.

Esposito G, Vitale AM, Leijten FP, Strik AM, Koonen-Reemst AM, Yurttas P, Robben TJ, Coonrod S \& Gossen JA 2007 Peptidylarginine deiminase (PAD) 6 is essential for oocyte cytoskeletal sheet formation and female fertility. Molecular and Cellular Endocrinology 273 25-31.

Evsikov AV, Graber JH, Brockman JM, Hampl A, Holbrook AE, Singh P, Eppig J, Solter D \& Knowles BB 2006 Cracking the egg: molecular dynamics and evolutionary aspects of the transition from the fully grown oocyte to embryo. Genes and Development 20 2713-2727.

Faircloth LM, Churchill PF, Caldwell GA \& Caldwell KA 2009 The microtubule-associated protein, NUD-1, exhibits chaperone activity in vitro. Cell Stress and Chaperones 14 95-103.

FitzHarris G, Marangos P \& Carroll J 2007 Changes in endoplasmic reticulum structure during mouse oocyte maturation are controlled by the cytoskeleton and cytoplasmic dynein. Developmental Biology 305 133-144.

Gurtu VE, Verma S, Grossmann AH, Liskay RM, Skarnes WC \& Baker SM 2002 Maternal effect for DNA mismatch repair in the mouse. Genetics $160271-277$.

Hamatani T, Carter MG, Sharov AA \& Ko MS 2004a Dynamics of global gene expression changes during mouse preimplantation development. Developmental Cell 6 117-131.

Hamatani T, Falco G, Carter MG, Akutsu H, Stagg CA, Sharov AA, Dudekula DB, VanBuren V \& Ko MSH 2004b Age-associated alteration of gene expression patterns in mouse oocytes. Human Molecular Genetics 132263.

Hao Z, Stoler MH, Sen B, Shore A, Westbrook A, Flickinger CJ, Herr JC \& Coonrod SA 2002 TACC3 expression and localization in the murine egg and ovary. Molecular Reproduction and Development 63 291-299.

Herr JC, Chertihin O, Digilio L, Jha KN, Vemuganti S \& Flickinger CJ 2008 Distribution of RNA binding protein MOEP19 in the oocyte cortex and early embryo indicates pre-patterning related to blastomere polarity and trophectoderm specification. Developmental Biology 314 300-316.

Howell CY, Bestor TH, Ding F, Latham KE, Mertineit C, Trasler JM \& Chaillet JR 2001 Genomic imprinting disrupted by a maternal effect mutation in the Dnmt1 gene. Cell 104 829-838.

Jones KT 2005 Mammalian egg activation: from $\mathrm{Ca}^{2+}$ spiking to cell cycle progression. Reproduction 130813.

Josefsberg LBY, Galiani D, Dantes A, Amsterdam A \& Dekel N 2000 The proteasome is involved in the first metaphase-to-anaphase transition of meiosis in rat oocytes. Biology of Reproduction 621270.

Joshi S, Davies H, Sims LP, Levy SE \& Dean J 2007 Ovarian gene expression in the absence of FIGLA, an oocyte-specific transcription factor. BMC Developmental Biology 767.

Kitagawa K, Skowyra D, Elledge SJ, Harper JW \& Hieter P 1999 SGT1 encodes an essential component of the yeast kinetochore assembly pathway and a novel subunit of the SCF ubiquitin ligase complex. Molecular Cell 4 21-33.

Li L, Baibakov B \& Dean J 2008 A subcortical maternal complex essential for preimplantation mouse embryogenesis. Developmental Cell 15 $416-425$.

Liang LF, Chamow SM \& Dean J 1990 Oocyte-specific expression of mouse Zp-2: developmental regulation of the zona pellucida genes. Molecular Biology of the Cell 10 1507-1515.

Lin SH, Nishino M, Luo W, Aumais JP, Galfione M, Kuang J \& Yu-Lee L 2003 Inhibition of prostate tumor growth by overexpression of NudC, a microtubule motor-associated protein. Oncogene 23 2499-2506.

Ma J, Zeng F, Schultz RM \& Tseng H 2006 Basonuclin: a novel mammalian maternal-effect gene. Development 133 2053-2062.

Manejwala FM, Logan CY \& Schultz RM 1991 Regulation of hsp70 mRNA levels during oocyte maturation and zygotic gene activation in the mouse. Developmental Biology 144301.

Mangia F \& Epstein CJ 1975 Biochemical studies of growing mouse oocytes: preparation of oocytes and analysis of glucose-6-phosphate dehydrogenase and lactate dehydrogenase activities. Developmental Biology 45211. 
Martins T, Maia AF, Steffensen S \& Sunkel CE 2009 Sgt1, a co-chaperone of Hsp90 stabilizes Polo and is required for centrosome organization. EMBO Journal 28 234-247.

Mashimo T, Glaser P, Lucas M, Simon-Chazottes D, Ceccaldi PE, Montagutelli X, DesprËs P \& Gü̈net JL 2003 Structural and functional genomics and evolutionary relationships in the cluster of genes encoding murine 2, 5 -oligoadenylate synthetases. Genomics 82 537-552.

Mertineit C, Yoder JA, Taketo T, Laird DW, Trasler JM \& Bestor TH 1998 Sex-specific exons control DNA methyltransferase in mammalian germ cells. Development 125889.

Metchat A, Akerfelt M, Bierkamp C, Delsinne V, Sistonen L, Alexandre H \& Christians ES 2009 Mammalian heat shock factor 1 is essential for oocyte meiosis and directly regulates Hsp90alpha expression. Journal of Biological Chemistry 284 9521-9528.

Oh B, Hwang SY, Solter D \& Knowles BB 1997 Spindlin, a major maternal transcript expressed in the mouse during the transition from oocyte to embryo. Development 124493.

Oh B, Hampl A, Eppig J,, Solter D \& Knowles BB 1998 SPIN, a substrate in the MAP kinase pathway in mouse oocytes. Molecular Reproduction and Development 50 240-249.

Ohsugi M, Zheng P, Baibakov B, Li L \& Dean J 2008 Maternally derived FILIA-MATER complex localizes asymmetrically in cleavage-stage mouse embryos. Development 135 259-269.

Patterson SD \& Aebersold RH 2003 Proteomics: the first decade and beyond. Nature Genetics 33 311-323.

Payer B, Saitou M, Barton SC, Thresher R, Dixon JP, Zahn D, Colledge WH, Carlton MB, Nakano T \& Surani MA 2003 Stella is a maternal effect gene required for normal early development in mice. Current Biology 13 2110-2117.

Rodrigues P, Limback D, McGinnis LK, Plancha CE \& Albertini DF 2008 Oogenesis: prospects and challenges for the future. Journal of Cellular Physiology 216 355-365.

Schneider L, Essmann F, Kletke A, Rio P, Hanenberg H, Wetzel W, Schulze-Osthoff K, Nurnberg B \& Piekorz RP 2007 The transforming acidic coiled coil 3 protein is essential for spindle-dependent chromosome alignment and mitotic survival. Journal of Biological Chemistry 28229273.

Schultz RM 2002 The molecular foundations of the maternal to zygotic transition in the preimplantation embryo. Human Reproduction Update $8323-331$.

Schultz RM \& Wassarman PM 1977 Biochemical studies of mammalian oogenesis: protein synthesis during oocyte growth and meiotic maturation in the mouse. Journal of Cell Science 24 167-194.

Seydoux G \& Braun RE 2006 Pathway to totipotency: lessons from germ cells. Cell 127 891-904.

Steensgaard P, GarrË M, Muradore I, Transidico P, Nigg EA, Kitagawa K, Earnshaw WC, Faretta M \& Musacchio A 2004 Sgt1 is required for human kinetochore assembly. EMBO Reports 5626.

Stemmann O, Neidig A, Köcher T, Wilm M \& Lechner J 2002 Hsp90 enables Ctf13p/Skp1p to nucleate the budding yeast kinetochore. PNAS 998585.

Sternlicht AL \& Schultz RM 1981 Biochemical studies of mammalian oogenesis: kinetics of accumulation of total and poly(A)-containing RNA during growth of the mouse oocyte. Journal of Experimental Zoology 215 $191-200$

Tanaka TS, Lopez de Silanes I, Sharova LV, Akutsu H, Yoshikawa T, Amano H, Yamanaka S, Gorospe M \& Ko MS 2006 Esg1, expressed exclusively in preimplantation embryos, germline, and embryonic stem cells, is a putative RNA-binding protein with broad RNA targets. Development, Growth and Differentiation 48 381-390.

Tong ZB \& Nelson LM 1999 A mouse gene encoding an oocyte antigen associated with autoimmune premature ovarian failure. Endocrinology 140 3720-3726.

Tong ZB, Gold L, Pfeifer KE, Dorward H, Lee E, Bondy CA, Dean J \& Nelson LM 2000a Mater, a maternal effect gene required for early embryonic development in mice. Nature Genetics 26 267-268.

Tong ZB, Nelson LM \& Dean J $2000 b$ Mater encodes a maternal protein in mice with a leucine-rich repeat domain homologous to porcine ribonuclease inhibitor. Mammalian Genome 11 281-287.

Tong ZB, Bondy CA, Zhou J \& Nelson LM 2002 A human homologue of mouse Mater, a maternal effect gene essential for early embryonic development. Human Reproduction 17 903-911.
Tutuncu L, Stein P, Ord TS, Jorgez CJ \& Williams CJ 2004 Calreticulin on the mouse egg surface mediates transmembrane signaling linked to cell cycle resumption. Developmental Biology 270246.

Underwood KW, Song C, Kriz RW, Chang XJ, Knopf JL \& Lin LL 1998 A novel calcium-independent phospholipase A2, CPLA2-gamma, that is prenylated and contains homology to CPLA2. Journal of Biological Chemistry $27321926-21932$.

Vitale A, Perlin J, Leonelli L, Herr J, Wright P, Digilio L \& Coonrod S 2005 Mouse cPLA2gamma, a novel oocyte and early embryo-abundant phospholipase A2 gamma-like protein, is targeted to the nuclear envelope during germinal vesicle breakdown. Developmental Biology 282 374-384.

Vitale AM, Calvert ME, Mallavarapu M, Yurttas P, Perlin J, Herr J \& Coonrod S 2007 Proteomic profiling of murine oocyte maturation. Molecular Reproduction and Development 74 608-616.

Wan LB, Pan H, Hannenhalli S, Cheng Y, Ma J, Fedoriw A, Lobanenkov V, Latham KE, Schultz RM \& Bartolomei MS 2008 Maternal depletion of CTCF reveals multiple functions during oocyte and preimplantation embryo development. Development 135 2729-2738.

Wang QT, Piotrowska K, Ciemerych MA, Milenkovic L, Scott MP, Davis RW \& Zernicka-Goetz M 2004 A genome-wide study of gene activity reveals developmental signaling pathways in the preimplantation mouse embryo. Developmental Cell 6 133-144.

Wassarman PM \& Josefowicz WJ 1978 Oocyte development in the mouse: an ultrastructural comparison of oocytes isolated at various stages of growth and meiotic competence. Journal of Morphology 156 209-235.

Weakley BS 1969 Initial stages in the formation of cytoplasmic lamellae in the hamster oocyte and the identification of associated electron-dense particles. Cell and Tissue Research 97 438-448.

Western P, Maldonado-Saldivia J, van den Bergen J, Hajkova P, Saitou M, Barton S \& Surani MA 2005 Analysis of Esg1 expression in pluripotent cells and the germline reveals similarities with Oct4 and Sox2 and differences between human pluripotent cell lines. Stem Cells 23 1436-1442.

Wright PW, Bolling LC, Calvert ME, Sarmento OF, Berkeley EV, Shea MC, Hao Z, Jayes FC, Bush LA, Shetty J et al. 2003 ePAD, an oocyte and early embryo-abundant peptidylarginine deiminase-like protein that localizes to egg cytoplasmic sheets. Developmental Biology 256 73-88.

Wu X, Viveiros MM, Eppig JJ, Bai Y, Fitzpatrick SL \& Matzuk MM 2003 Zygote arrest 1 (Zar1) is a novel maternal-effect gene critical for the oocyte-to-embryo transition. Nature Genetics 33 187-191.

Yamaguchi M 2000 Role of regucalcin in calcium signaling. Life Sciences 66 1769-1780.

Yan W, Ma L, Stein P, Pangas SA, Burns KH, Bai Y, Schultz RM \& Matzuk MM 2005 Mice deficient in oocyte-specific oligoadenylate synthetase-like protein OAS1D display reduced fertility. Molecular and Cellular Biology 254615.

Yanagimachi R 1994 Mammalian fertilization. In Physiology of Reproduction, pp 189-317. Eds E Knobil \& JD Neill. New York: Raven Press.

Yuan H, Zhang P, Qin L, Chen L, Shi S, Lu Y, Yan F, Bai C, Nan X \& Liu D 2007 Overexpression of SPINDLIN1 induces cellular senescence, multinucleation and apoptosis. Gene 410 67-74.

Yurttas P, Vitale AM, Fitzhenry RJ, Cohen-Gould L, Wu W, Gossen JA \& Coonrod SA 2008 Role for PADI6 and the cytoplasmic lattices in ribosomal storage in oocytes and translational control in the early mouse embryo. Development 135 2627-2636.

Zeng F, Baldwin DA \& Schultz RM 2004 Transcript profiling during preimplantation mouse development. Developmental Biology 272 483-496.

Zhang P, Ni X, Guo Y, Guo X, Wang Y, Zhou Z, Huo R \& Sha J 2009 Proteomic-based identification of maternal proteins in mature mouse oocytes. BMC Genomics 10348.

Zheng P \& Dean J 2009 Role of Filia, a maternal effect gene, in maintaining euploidy during cleavage-stage mouse embryogenesis. PNAS 106 7473-7478.

Received 1 December 2009

First decision 5 January 2010

Accepted 26 January 2010 